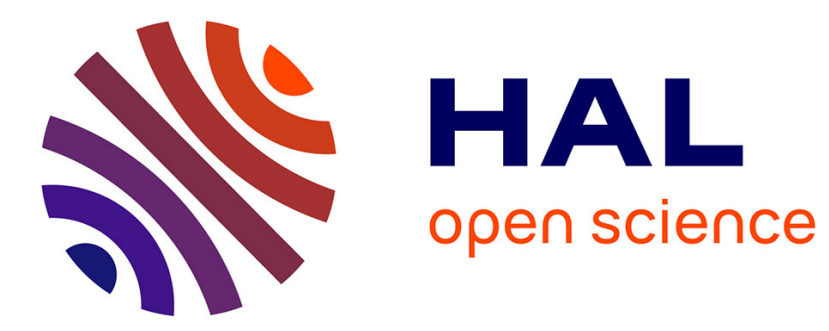

\title{
Aluminum to titanium laser welding-brazing in V-shaped grooveI
}

I Tomashchuk, P Sallamand, A. Méasson, E Cicala, M Duband, P Peyre

\section{To cite this version:}

I Tomashchuk, P Sallamand, A. Méasson, E Cicala, M Duband, et al.. Aluminum to titanium laser welding-brazing in V-shaped grooveI. Journal of Materials Processing Technology, 2017, 245, pp.24-36. 10.1016/j.jmatprotec.2017.02.009 . hal-01494324

\section{HAL Id: hal-01494324 https://hal.science/hal-01494324}

Submitted on 23 Mar 2017

HAL is a multi-disciplinary open access archive for the deposit and dissemination of scientific research documents, whether they are published or not. The documents may come from teaching and research institutions in France or abroad, or from public or private research centers.
L'archive ouverte pluridisciplinaire HAL, est destinée au dépôt et à la diffusion de documents scientifiques de niveau recherche, publiés ou non, émanant des établissements d'enseignement et de recherche français ou étrangers, des laboratoires publics ou privés. 


\title{
Aluminum to titanium laser welding-brazing in V-shaped groove
}

\author{
I. Tomashchuk ${ }^{\mathrm{a}, *}$, P. Sallamand ${ }^{\mathrm{a}}$, A. Méasson ${ }^{\mathrm{a}}$, E. Cicala $^{\mathrm{a}}$, M. Duband $^{\mathrm{a}}$, P. Peyre $^{\mathrm{b}}$ \\ a Laboratoire Interdisciplinaire Carnot de Bourgogne, UMR 6303 CNRS-Université de Bourgogne Franche Comté, 12, rue de la Fonderie, 71200 Le Creusot, \\ France \\ b PIMM Laboratory, UMR 8006 CNRS-Arts et Métiers ParisTech, 151 Bd de l'Hôpital, 75013 Paris, France
}

\section{A R T I C L E I N F O}

\section{Article history:}

Received 10 October 2016

Received in revised form 17 February 2017

Accepted 18 February 2017

Available online 21 February 2017

\section{Keywords:}

Laser welding

Dissimilar metal joint

Titanium alloys

Aluminum alloys

\begin{abstract}
A B S T R A C T
Laser assisted joining of AA5754 aluminum alloy to T40 titanium with use of Al-Si filler wires was carried out. Continuous Yb:YAG laser beam was shaped into double spot tandem and defocalized to cover larger interaction zone in $\mathrm{V}$ shaped groove. Experimental design method was applied to study the influence of operational parameters on the tensile properties of the joints. Microstructure examination and fractography study were carried out to understand the relation between local phase content and fracture mode.

Within defined window of operational parameters, statistically important factors that influenced the strength of T40 to AA5754 joints in V groove configuration were Si content in the filler metal and groove opening angle on T40 side. The best quality joint showed joint coefficient of $90 \%$ (or $200 \mathrm{MPa}$ of apparent UTS). Tensile strength of the joints was found to be determined by the proportion between well-developed and under-developed reaction zones of T40/melted zone interface. The formation of $2-25 \mu \mathrm{m}$ thick Si-rich interlayers composed by $\mathrm{Ti}_{5} \mathrm{Si}_{3}$ and $\tau_{2}$ proved to enhance the strength of brazed interface. The creation of very thin $(<0.5 \mu \mathrm{m})$ Si-rich layers at the bottom of the groove was found not sufficient to establish mechanical continuity of the joint and thus should be avoided.
\end{abstract}

\section{Introduction}

Dissimilar joining of aluminum and titanium alloys in lightened hybrid structures becomes relevant for application in transport and aircraft industries. However, it remains a difficult task because of important mismatch in physical properties, limited mutual solubility and formation of brittle intermetallic phases in aluminum-titanium (Al-Ti) system, reported by Raghavan (2005). Successful joining of aluminum to titanium demands prevention of local accumulation of intermetallic phases, especially of $\mathrm{TiAl}_{3}$.

Direct laser joining of titanium alloys to aluminum alloys in keyhole mode often results in cold cracking of the weld. Majumdar et al., 1997 reported that shift of $\mathrm{CO}_{2}$ laser beam to titanium side during welding of Ti6Al4V to aluminum alloy resulted in formation of numerous cracks in the zones rich in TiAl and $\mathrm{Al}_{3} \mathrm{Ti}$. However, Kreimeyer et al. (2005) reported the successful joining of AA6016 to Ti6Al4V with $\mathrm{CO}_{2}$ laser shifted at $0.3-0.5 \mathrm{~mm}$ to titanium side. In this case, aluminum side was only slightly melted, and, consequently, the formation of intermetallic phases was reduced. Later, same result was confirmed by Casalino et al. (2015): intermetal-

\footnotetext{
* Corresponding author.

E-mail address: iryna.tomashchuk@u-bourgogne.fr (I. Tomashchuk).
}

lic zone thickness was reduced down to $1 \mu \mathrm{m}$ and was no more an initiator of fracture during tensile test. Song et al. (2013) tried opposite approach by shifting the laser beam completely to aluminum side and obtained crack-free joints. However, thickness of zone rich in intermetallic phases remained important $(260 \mu \mathrm{m})$ and average tensile strength of the welds did not overpass $64 \%$ of aluminum alloy. Tomashchuk et al. (2015) reported that high speed welding ( $>5 \mathrm{~m} / \mathrm{min}$ ) by Yb:YAG laser could prevent important mixing between two melted materials and confirmed that laser beam offset at aluminum side is beneficial for weld regularity and tensile strength. Gao et al. (2013) carried out hybrid laser-CMT welding of AA6061 to Ti6Al4V with Al-12Si filler wire. Accurate control of total heat input and fluid flow in the melted zone allowed reducing zone of intermetallic phase down to $1 \mu \mathrm{m}$ and reach joint coefficient of 95.5\% of AA6061. All authors highlight the necessity to reduce the interaction between Ti and Al to thin diffusive interface. That is why many studies concentrate on strong brazing approach, when only aluminum side of the joint undergoes fusion.

Very promising results on joining of aluminum alloys with titanium alloys were obtained by laser assisted welding-brazing. The main advantage of laser beam in this case consists in providing accurate energy supply with well-known distribution law, which allows control the thickness of intermetallic layers. Vaidya et al. (2010) reported the formation of $1.8 \mu \mathrm{m}$ thick intermetallic layer 

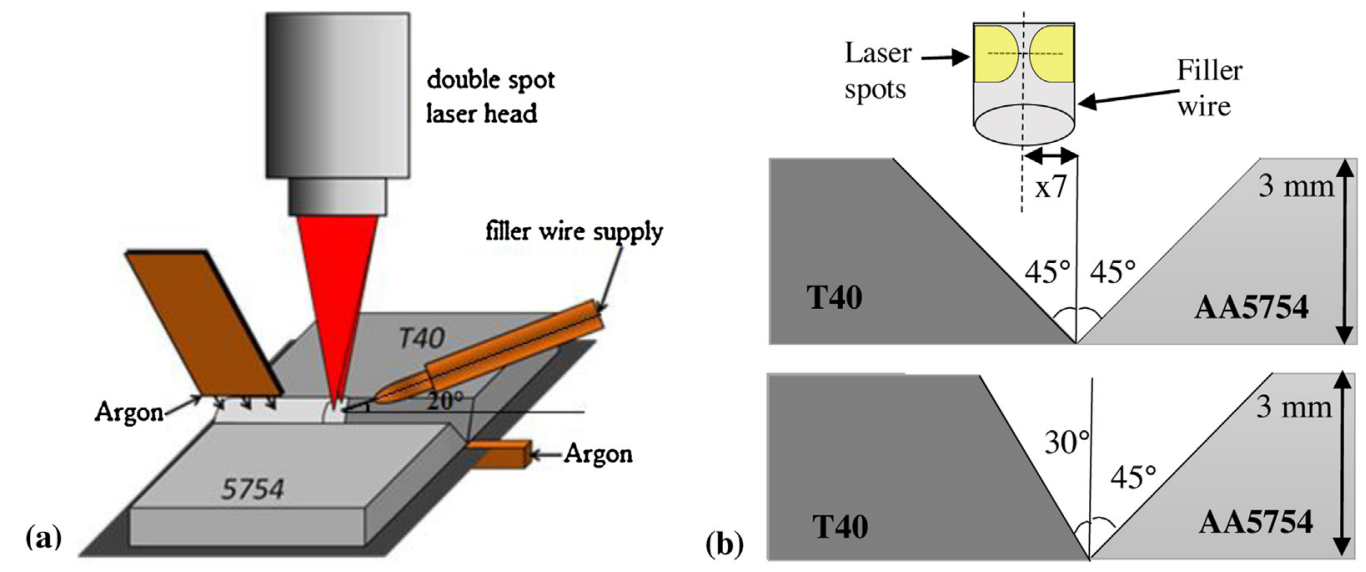

Fig. 1. Welding configuration (a) and draft of the groove (b).

Table 1

Chemical composition and melting temperature of raw materials.

\begin{tabular}{|c|c|c|}
\hline & Chemical composition (wt.\%) & Melting range $\left({ }^{\circ} \mathrm{C}\right)$ \\
\hline AA5754 & Al: balance; Mg: $6 ; \mathrm{Si}: \leq 1$ & $560-629$ \\
\hline T40 & Ti: balance; O: $0.25 ; \mathrm{N}: 0.03 ; \mathrm{C}: 0.08 ; \mathrm{H}: 0.015 ; \mathrm{F}: 0.3$ & 1668 \\
\hline 4043 & Al: balance; Si: 5.2; Fe: $\leq 0.08 ; \mathrm{Zn}: \leq 0.1 ; \mathrm{Cu}: \leq 0.3 ; \mathrm{Mn}: \leq 0.05 ; \mathrm{Mg}: \leq 0.05 ; \mathrm{Ti}: \leq 0.1$ & $574-632$ \\
\hline 4047 & Al: balance; Si: $12.0 ; \mathrm{Fe}: 0.8 ; \mathrm{Zn}: 0.2 ; \mathrm{Cu}: \leq 0.3 ; \mathrm{Mn}: 0.15 ; \mathrm{Mg}: 0.1$ & $577-582$ \\
\hline
\end{tabular}

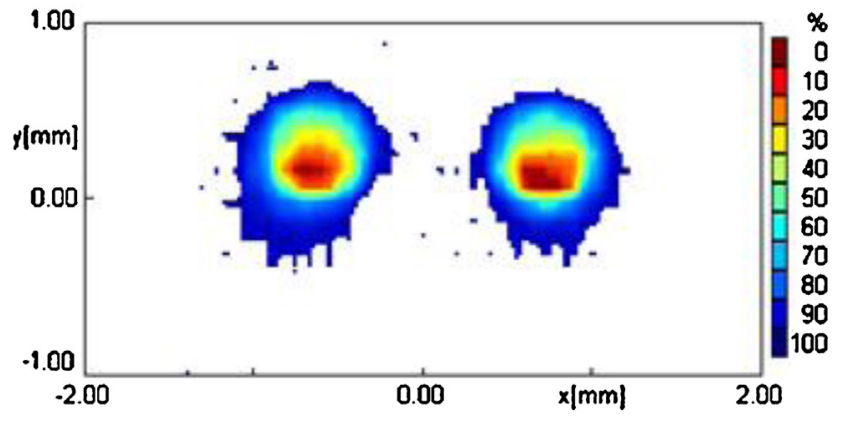

(a)

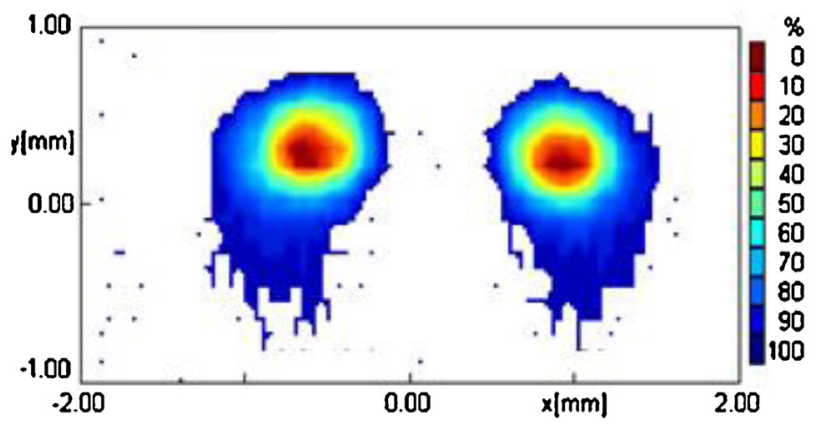

(b)

Fig. 2. Laser beam profiles (expressed as\% of beam power contained in the area): defocalization of $+4 \mathrm{~mm}$ (a) and of $+8 \mathrm{~mm}$ (b)

at the interface between U-shaped AA6065 plate and Ti6Al4V sheet welded by laser in conduction mode (without keyhole formation). In this case, fracture occurred in Al-rich melted zone. Peyre et al. (2014) performed laser welding-brazing of AA 6061 aluminum alloy to Ti6Al4V in lap-joint configuration with no filler material and with Al-5Si filler wire, but the effect of Si on mechanical properties of the joint was found unnoticeable.

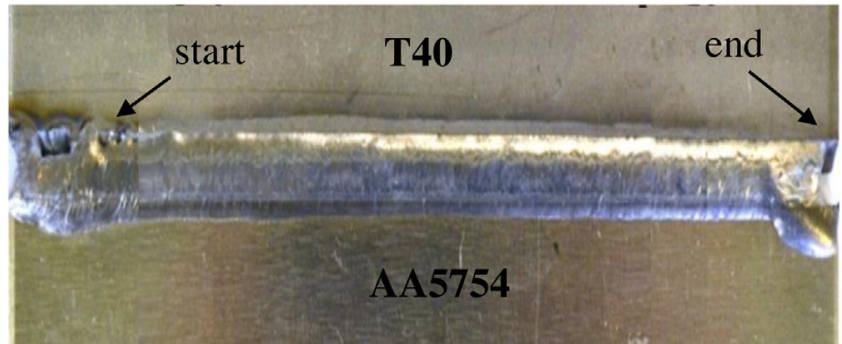

(a)

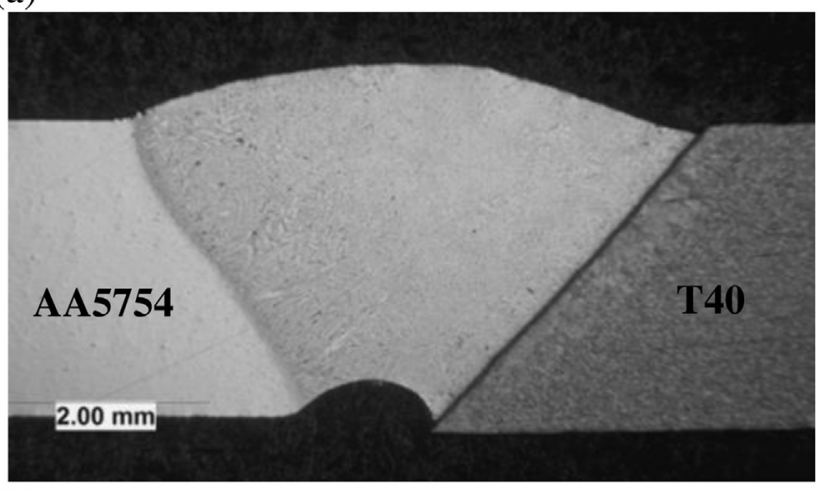

(b)

Fig. 3. Typical aspect and morphology of T40 to AA5754 joint: top view (a) and cross-section (b) of sample 2.

Chen et al. (2010a) studied laser brazing of aluminum to titanium in V-shaped groove configuration with Al-12Si filler wire. They reported that accumulation of $\mathrm{Si}$ close to solid $\mathrm{Ti}$ interface led to the formation of thin layer of ternary phase $\mathrm{Ti}_{7} \mathrm{Al}_{5} \mathrm{Si}_{12}$ preferentially to brittle $\mathrm{TiAl}_{3}$. According to the thermodynamic model proposed by Chen et al. (2010a), the accumulation of Si next to solid Ti interface strongly depends on local quantity of Ti that diffused into liquid zone. Minimal chemical potential of the system is reached when molar fraction of Ti approaches 0.5 . The accumulation of Si led to the formation of compact layer of ternary 

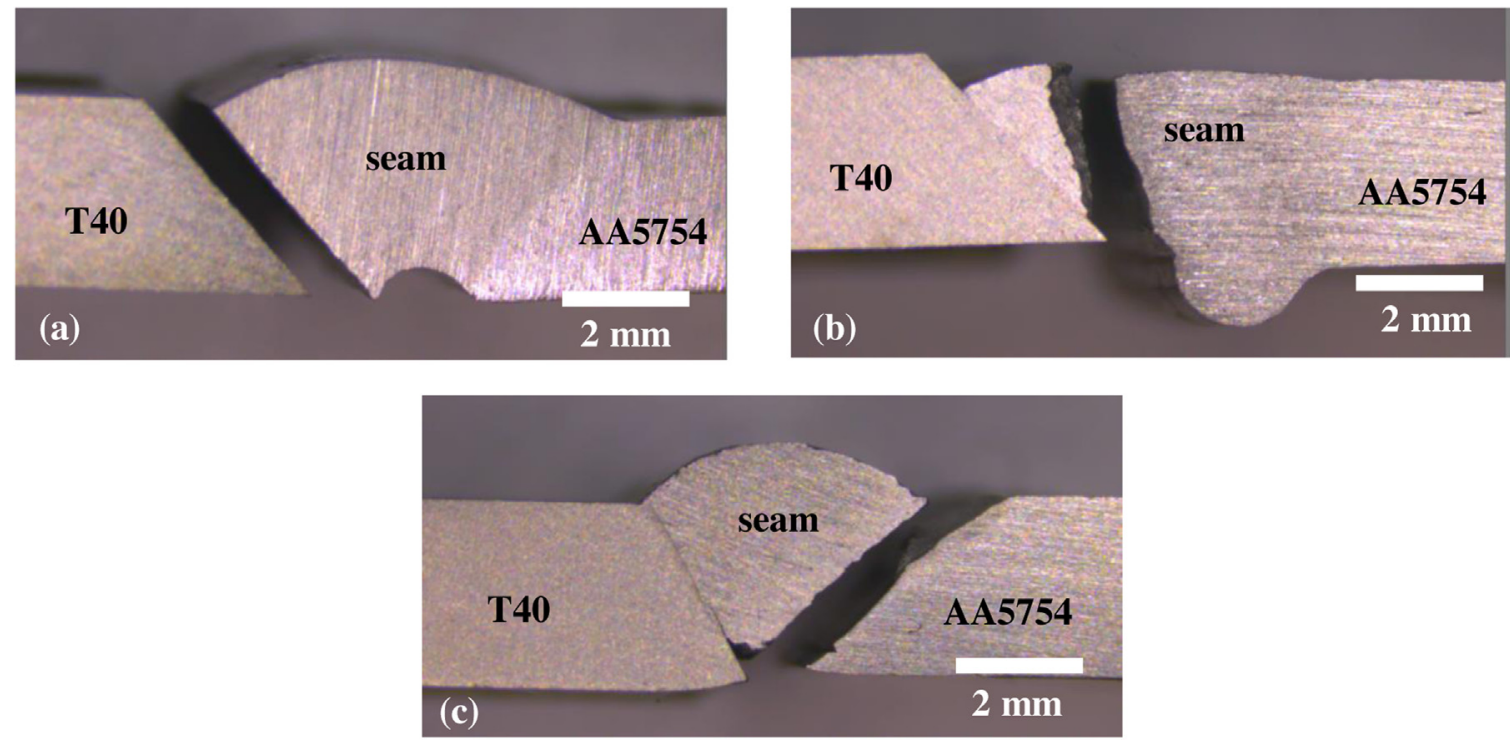

Fig. 4. Cross-sections of fractured welds: sample 2 (a), sample 7 (b) and sample 4 (c).

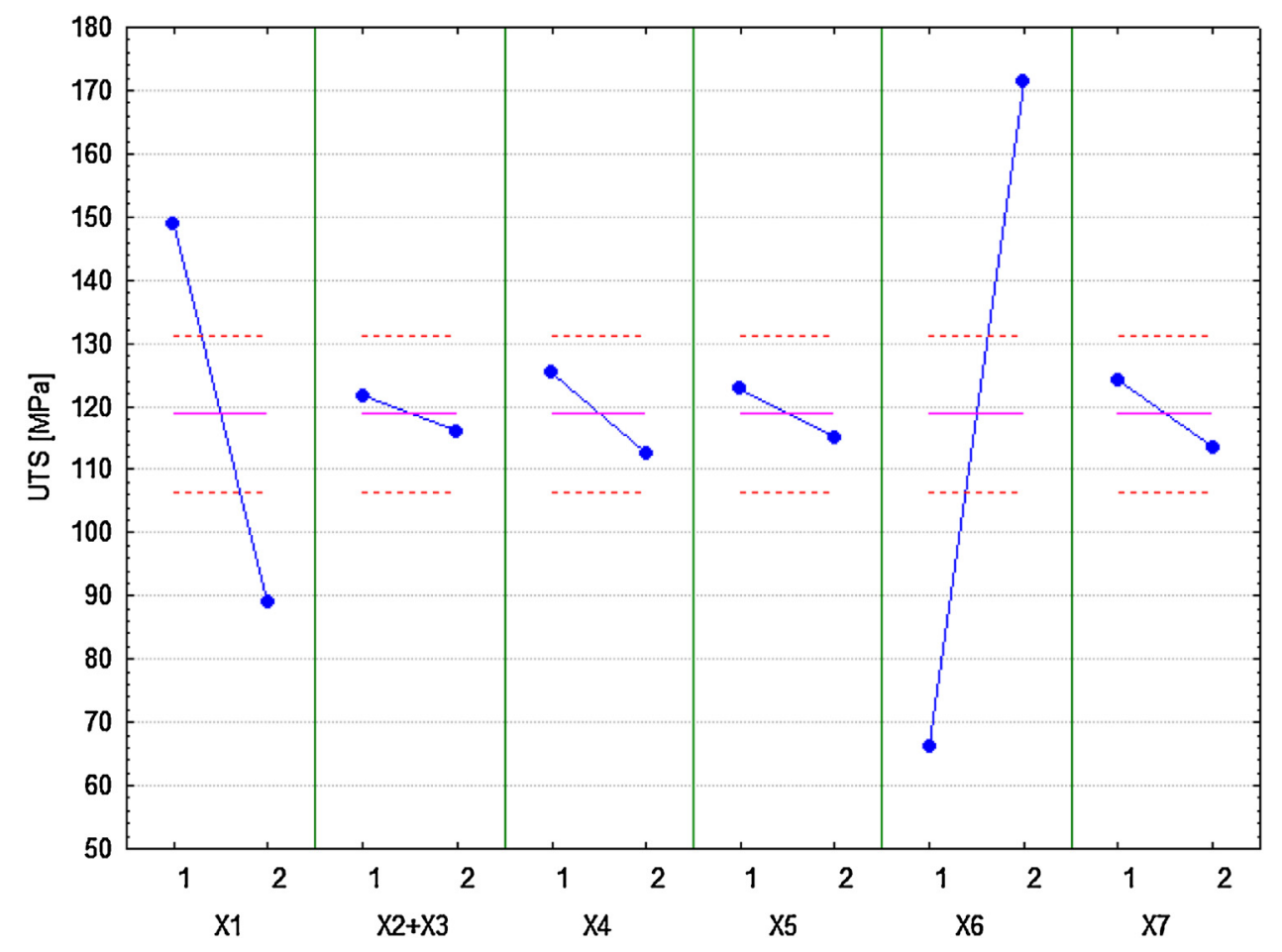

Fig. 5. Diagram of effects (confidence intervals for $\mathrm{p}=0.05$ are indicated with dot lines).

phase $\mathrm{Ti}_{7} \mathrm{Al}_{5} \mathrm{Si}_{12}$ followed by columnar layer of $\mathrm{Ti}(\mathrm{Al}, \mathrm{Si})_{3}$. Later, Chen et al. (2011b) elucidated more in detail the mechanism of these interfacial reactions and highlighted barrier role of $\mathrm{Ti}_{7} \mathrm{Al}_{5} \mathrm{Si}_{12}$ that prevents diffusion of $\mathrm{Ti}$ in the melted zone and in this way reduces the quantity of brittle Al-Ti intermetallics.

Chen et al. (2010b) demonstrated the influence of heat flow along solid Ti side on the morphology of resulting Si-containing microstructures. In this experiment, the groove was machined only at aluminum alloy side, while titanium interface remained perpendicular to the top surface of the plate. Laser beam was modulated into rectangular spot with Gaussian distribution in cross-direction and uniform distribution along the joint line. It was observed that while the top of the interface demonstrated well-advanced inter- facial reactions, the bottom part suffered from lack of energy and served a start-point for crack propagation.

The uniform morphology of interfacial microstructures on solid Ti side was obtained by Chen et al. (2011a) when $45^{\circ}$ grooves both from titanium and aluminum sides were associated with modulated rectangular spot of the same shape as proposed by Chen et al. (2010b). According to the numerical model of heat transfer proposed by Chen et al. (2011a), the use of rectangular spot allowed the reducing of the difference of temperatures attained in different parts of titanium groove. In this way, UTS of $278 \mathrm{MPa}$ was attained, and fracture took place in the seam. On the other hand, the use of common Gaussian distribution of laser energy resulted in impor- 

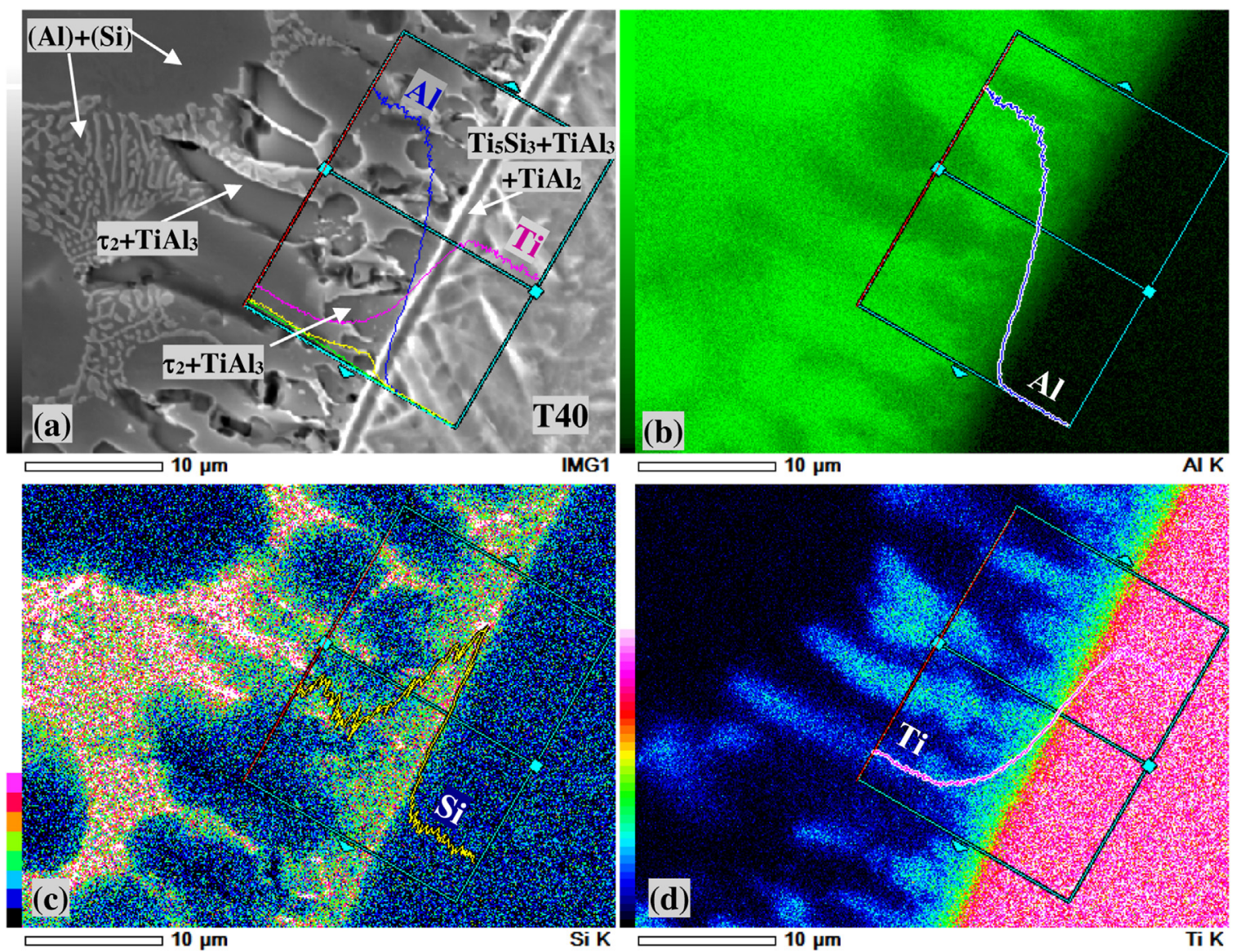

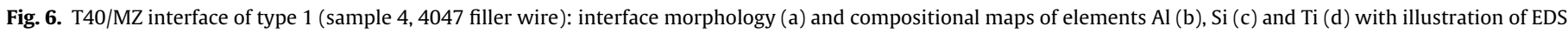
signal variation across the interface.

Table 2

Influencing factors included in experimental design.

\begin{tabular}{llll}
\hline Influencing factors & Code & Level 1 & Level 2 \\
\hline Filler wire material & x1 & 4047 & 4043 \\
Laser power (W) & x2 & 3000 & 3600 \\
Filler supply rate (m/min) & x3 & 1.8 & 2.2 \\
Welding speed (m/min) & x4 & 0.45 & 0.55 \\
Defocalization from the top surface (mm) & x5 & +8 & +4 \\
Groove opening angle T40/AA5754 & x6 & $30^{\circ} / 45^{\circ}$ & $45^{\circ} / 45^{\circ}$ \\
Laser offset from joint line to T40 (mm) & x7 & 0.4 & 0.9 \\
\hline
\end{tabular}

tant variations of interfacial microstructures across the interface and poor UTS values.

The present study is focused on the problem of efficient brazing of AA5754 alloy to T40 titanium with use of Al-Si filler wires of different composition. Defocalized Yb:YAG laser shaped into double half-spot configuration is used to enlarge interaction zone. Experimental design method is used to study the influence of operational conditions on the tensile properties of the joints.

\section{Experimental set-up}

$3 \mathrm{~mm}$ thick aluminum alloy AA5754 and titanium T40 plates and Al-Si based filler wires 4043 (Al-5Si) and 4047 (Al-12Si) of $1.6 \mathrm{~mm}$ in diameter were used. Chemical composition of raw materials is given in Table 1.

Grooves with opening angles of $45^{\circ}$ or $30^{\circ}$ were machined at T40 side, according to experimental design plan (Table 3), whereas for AA5754 opening angle was fixed to $45^{\circ}$. Welding configuration and sketch of the grooves are provided at Fig. 1.
Table 3

Experimental layout.

\begin{tabular}{llllllll}
\hline \multirow{2}{*}{ No } & \multicolumn{7}{l}{ Influencing factors } \\
\cline { 2 - 8 } & $\mathrm{x} 1$ & $\mathrm{x} 2$ & $\mathrm{x} 3$ & $\mathrm{x} 4$ & $\mathrm{x} 5$ & $\mathrm{x} 6$ & $\mathrm{x} 7$ \\
\hline 1 & 4047 & 3000 & 1.8 & 0.45 & 4 & $30^{\circ} / 45^{\circ}$ & 0.4 \\
2 & 4047 & 3000 & 1.8 & 0.55 & 8 & $45^{\circ} / 45^{\circ}$ & 0.9 \\
3 & 4047 & 3600 & 2.2 & 0.45 & 4 & $45^{\circ} / 45^{\circ}$ & 0.9 \\
4 & 4047 & 3600 & 2.2 & 0.55 & 8 & $30^{\circ} / 45^{\circ}$ & 0.4 \\
5 & 4043 & 3000 & 1.8 & 0.45 & 8 & $30^{\circ} / 45^{\circ}$ & 0.9 \\
6 & 4043 & 3000 & 1.8 & 0.55 & 4 & $45^{\circ} / 45^{\circ}$ & 0.4 \\
7 & 4043 & 3600 & 2.2 & 0.45 & 8 & $45^{\circ} / 45^{\circ}$ & 0.4 \\
8 & 4043 & 3600 & 2.2 & 0.55 & 4 & $30^{\circ} / 45^{\circ}$ & 0.9 \\
\hline
\end{tabular}

Welding experiments were performed with continuous Yb:YAG laser having maximal beam power of $6 \mathrm{~kW}$ and optical fiber with diameter of $600 \mu \mathrm{m}$. Double half-spot welding head with focus distance of $200 \mathrm{~mm}$ was used. Initial laser beam was divided by beam splitter and thus formed two inversed half-spots with Gaussian distribution separated by a distance of $1.2 \mathrm{~mm}$. This beam configuration allows to enlarge the interaction zone and to heat instantaneously base material and filler wire. In the present study, it was used in attempt to approach uniform temperature distribution on the walls of $\mathrm{V}$-shaped groove.

In order to define a new shape and energy distribution of resulting double half-spot tandem, the characterization of laser beam with diagnostic system Prometec Laserscope UFF100 was carried out, according to the method introduced by Liu and Leong (1992). This method consists in direct sampling of discrete portion of laser beam and recording of spatial power intensity. The Prometec Laserscope uses a hollow needle with a pinhole aperture which is rapidly 
Table 4

Tensile test results.

\begin{tabular}{|c|c|c|c|c|c|c|c|}
\hline \multirow[t]{2}{*}{ No } & \multicolumn{4}{|c|}{ Tensile force $(\mathrm{N} / \mathrm{mm})$} & \multirow[t]{2}{*}{ Apparent UTS (MPa) } & \multirow[t]{2}{*}{ Average elongation (mm) } & \multirow[t]{2}{*}{ Fracture position } \\
\hline & $\mathrm{F}_{1}$ & $\mathrm{~F}_{2}$ & $\mathrm{~F}_{3}$ & Average & & & \\
\hline 1 & 344 & 358 & 366 & 356 & 119 & 1.734 & T40/MZ interface \\
\hline 2 & 563 & 598 & 580 & 580 & 193 & 1.960 & $\mathrm{~T} 40 / \mathrm{MZ}$ interface \\
\hline 3 & 576 & 592 & 620 & 596 & 200 & 2.614 & T40/MZ interface \\
\hline 4 & 239 & 249 & 265 & 251 & 84 & 0.738 & $\begin{array}{l}\text { AA5754/MZ interface (lack of } \\
\text { fusion) }\end{array}$ \\
\hline 5 & 93 & 107 & 85 & 95 & 32 & 0.096 & T40/MZ interface \\
\hline 6 & 419 & 442 & 429 & 430 & 143 & 1.479 & $\begin{array}{l}\text { Initiated at } \mathrm{T} 40 / \mathrm{MZ} \text { interface } \\
\text { and propagated in Al-Si filler } \\
\text { wire }\end{array}$ \\
\hline 7 & 421 & 468 & 473 & 454 & 151 & 1.765 & $\begin{array}{l}\text { Initiated at } \mathrm{T} 40 / \mathrm{MZ} \text { interface } \\
\text { and propagated in Al-Si filler } \\
\text { wire }\end{array}$ \\
\hline 8 & 89 & 75 & 112 & 92 & 30 & 0.211 & T40/MZ interface \\
\hline
\end{tabular}
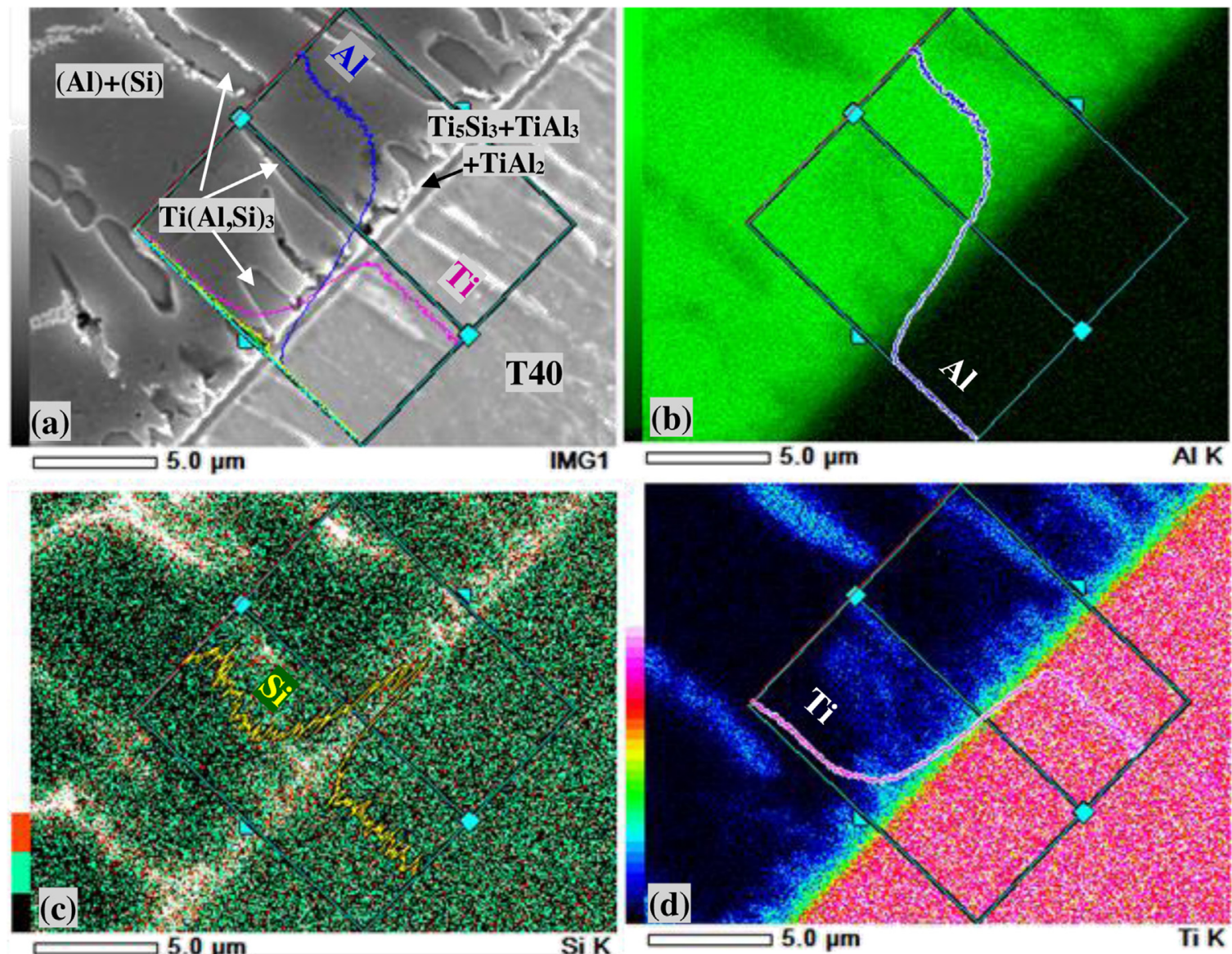

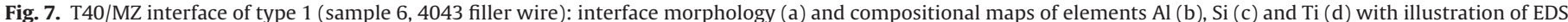
signal variation across the interface.

Table 5

$\mathrm{p}$ values of factors influencing tensile strength.

\begin{tabular}{lllllll}
\hline IF & $\mathrm{x} 1$ & $\mathrm{x} 2+\mathrm{x} 3$ & $\mathrm{x} 4$ & $\mathrm{x} 5$ & $\mathrm{x} 6$ & $\mathrm{x} 7$ \\
\hline $\mathrm{p}$ & 0.0463 & 0.3149 & 0.1914 & 0.2693 & 0.0264 & 0.2175 \\
\hline
\end{tabular}

swept through the laser beam (unfocused or focused) to measure the intensity distribution (Graham and Weckman, 1995).

Basing on the results of preliminary experimental study, important defocalization of double half-spot was adopted ( +4 to $+8 \mathrm{~mm}$ from the top surface of the plates). This allowed avoiding the melting of T40 side and noticeably enlarged the interaction zone. The analysis of acquired beam profiles showed rather symmetrical laser power distribution between two spots (Fig. 2): each spot contained $50 \%$ of initial laser power.

The plates were welded in V-grove configuration (Fig. 1a). As the distance between two laser spots was fixed to $1.2 \mathrm{~mm}$ and filler supply was coaxial to double half-spot tandem, the filler wire of $1.6 \mathrm{~mm}$ in diameter was melted by both spots and produced partial screening of groove surface from laser radiation (Fig. 1b).

Preliminary study showed that optimal position of double halfspot lies within +0.4 and $+0.9 \mathrm{~mm}$ laser offset to $\mathrm{T} 40$ side. The angle of $20^{\circ}$ between the filler wire and top surface of the plates was 

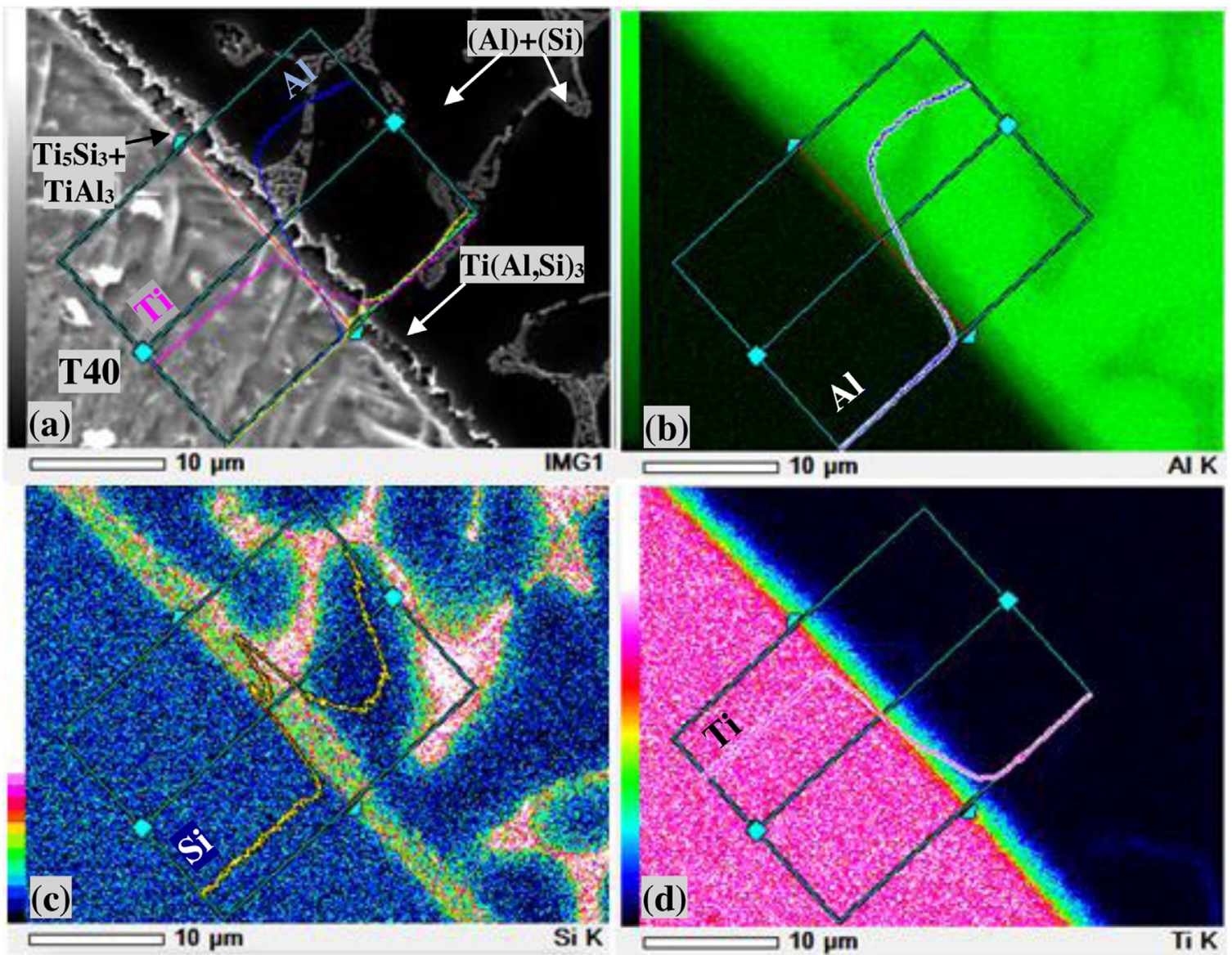

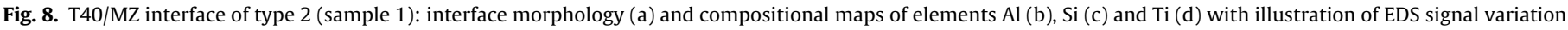
across the interface.

applied. Top and bottom gas protection was implied (pure argon with total debit of $201 / \mathrm{min}$ ).

After preliminary identification of the window of operational conditions, the factorial design plan for 2 levels without repetition was applied to quantify the influence of seven varying parameters on tensile strength of obtained joints. The influencing factors taken in consideration are given in Table 2. Following this experimental design, eight welding conditions were tested (Table 3 ).

Cross-sections of the welds were polished and etched with Keller's reagent. $20 \mathrm{~mm}$ large transversal cuts of the weld underwent tensile test. Three tensile tests per welding condition were made. Fracture surfaces from both sides of broken welds were examined.

Microstructure and chemical composition of samples were studied by scanning electron microscope (JEOL) with fast EDS analyzer. Two crosscuts per condition were observed.

UTS of the welds was evaluated at room temperature in tensile testing machine (MTS Insight $30 \mathrm{kN}$ ) at a crosshead speed of $8.3 \times 10^{-5} \mathrm{~m} / \mathrm{s}$ with rectangular samples of $20 \times 100 \mathrm{~mm}^{2}$. Mechanical stability of the welds was characterized by linear tensile force $(\mathrm{N} / \mathrm{mm})$ because of different areas of weld cross-sections and by apparent UTS (MPa) that neglects the variation of thickness between the weld and the plates.

The identification of phase composition on fractured surfaces was carried out by X-ray diffraction (PANalytical X'Pert PRO) using a cobalt target. Scanning range of $20-140^{\circ}$ with a step scan of $0.0167^{\circ}$ and counting time of 200 s per step were used.

\section{Results and discussion}

\subsection{General observations}

Under all tested operational conditions (Table 3) melting of T40 side was completely avoided, while slight melting of AA5754 took place. Melted zone (MZ) composition was found very close to that of filler material ( 10 or 4 wt.\% Si for 4047 and 4043 filler metals respectively, « 1 wt.\% Ti). Typical aspect and cross-section of the weld are illustrated at Fig. 3. No porosities or hot cracks were visible in the weld. The increase of grain size in HAZ of T40 was systematically observed. Heat affected zone can be observed only on T40 side where the increase of grain size took place. Typical defects of the melted zone are related with filling of the groove by melted wire. The bottom of T40 groove sometimes presents the lack of brazing or wettening, especially for $30^{\circ}$ groove angle.

Important variation of tensile properties depending on applied combination of influencing factors was observed (Table 4). The best joint (sample 3) showed tensile force of $596 \mathrm{~N} / \mathrm{mm}$ or $200 \mathrm{MPa}$ of apparent UTS, whereas the worst one (sample 8) showed only $92 \mathrm{~N} / \mathrm{mm}$ or $30 \mathrm{MPa}$. Joint coefficient calculated as

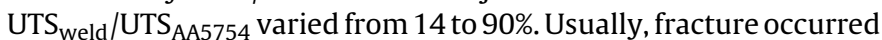
at the interface between T40 and melted zone (Fig. 4a). In samples 6 and 7 the crack was initiated at the bottom part of T40/MZ interface but then propagated in Al-Si filler wire (Fig. 4b). The reason of this behavior will be discussed in Section 3.3. In sample 4 fracture occurred at the interface between AA5754 and MZ (Fig. 4c). Close analysis of the weld showed that the origin of this behavior was 

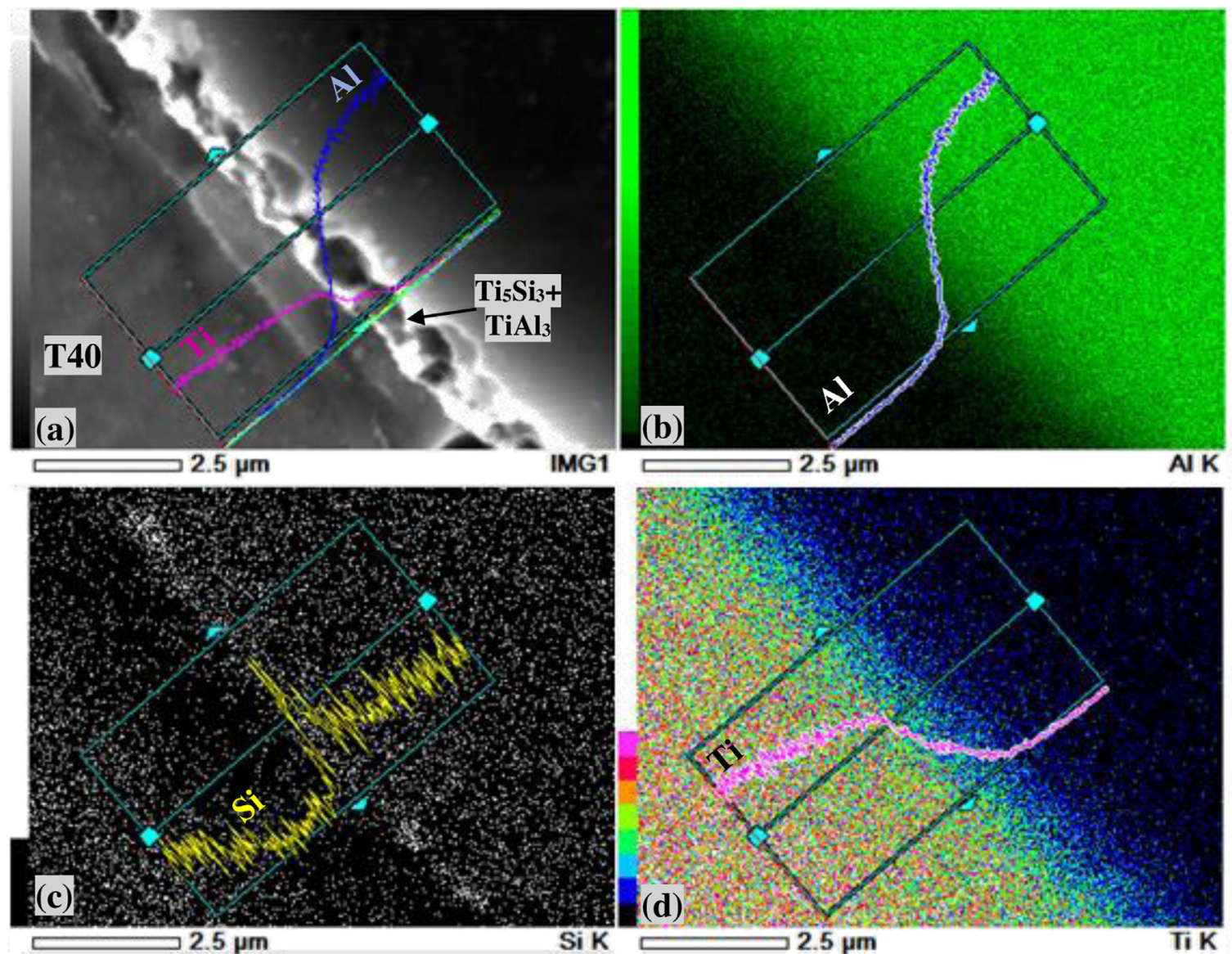

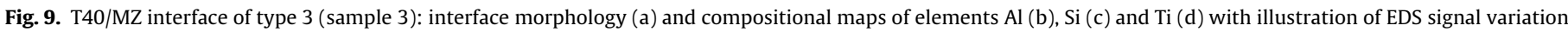
across the interface.

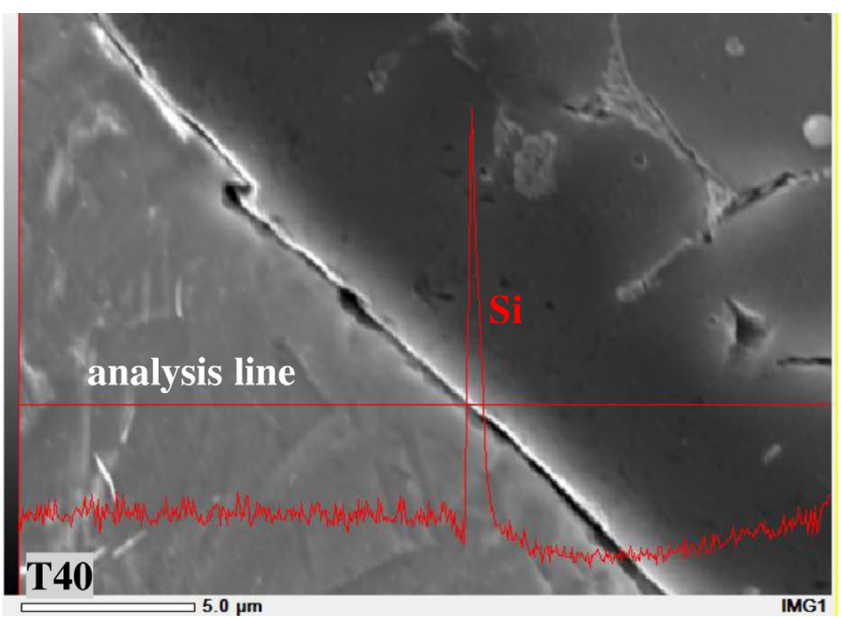

Fig. 10. T40/MZ interface of type 4 and evolution of EDS signal of Si along analysis line (bottom of sample 6).

a lack of fusion at this interface. For all samples, low elongation values were noticed.

The analysis of diagram of effects for chosen factors of influence (Fig. 5) revealed that the tensile properties of the welds are strongly influenced by groove opening angles (x6) and by the composition of filler material (x1). In concordance with results of Chen et al. (2010b), the use of filler wire with higher Si content (12 wt.\%) is beneficial for tensile properties of the welds. The addition of Si changes phase selection at the interface between solid titanium and melted zone. The formation of Si-rich phases and mild thermal cycle at titanium/melted zone interface can limit the diffusion of Ti in the melted zone and in this way reduce the quantity of brittle Al-Ti intermetallics. The opening angle of groove should be big enough to allow good wettability by liquid filler material. Therefore, the worst results were obtained with grooves having $30^{\circ}$ angle from $\mathrm{T} 40$ side. The quantification of significance of influencing factors is provided by p-values obtained with variance analysis ANOVA (Table 5). In order to decide whether the effect is significant or not, threshold value of $p=0.05$ (probability level of 95\%) was imposed (associated effects on average apparent UTS are provided in form of upper and lower limits on Fig. 5). In this particular study, it can be concluded that factors $\mathrm{x} 1$ (filler material) and $\mathrm{x} 6$ (opening angle) produced an effect strong enough to be considered as significant. Other factors like laser power, wire supply rate, welding speed, defocalization and offset from joint line had no significant influence on response function within defined window of operational parameters.

\subsection{Microstructure of T40/MZ interface}

The following study was focused on composition and morphology of T40/MZ dissimilar interface. It was found that up to four interface morphologies might coexist in a single sample because of a difference in local thermal history. Typical interface morphologies with associated phases are described below.The morphology of type 1 composed by well-developed columnar structure (Fig. 6) was usually observed at the top $1 / 3-1 / 2$ part of T40/MZ interface. Here, the thickness of the interface was comprised between 13 and $25 \mu \mathrm{m}$. Starting from T40 side, thin diffusion layer $(<0.5 \mu \mathrm{m})$ of $\mathrm{Al}$ in Ti was observed. It was followed by a 3-6 $\mu \mathrm{m}$ thick layer of Ti diffusion in the melted zone, where strong segregation of Si was observed. This interlayer differed in morphology and composition, depending 


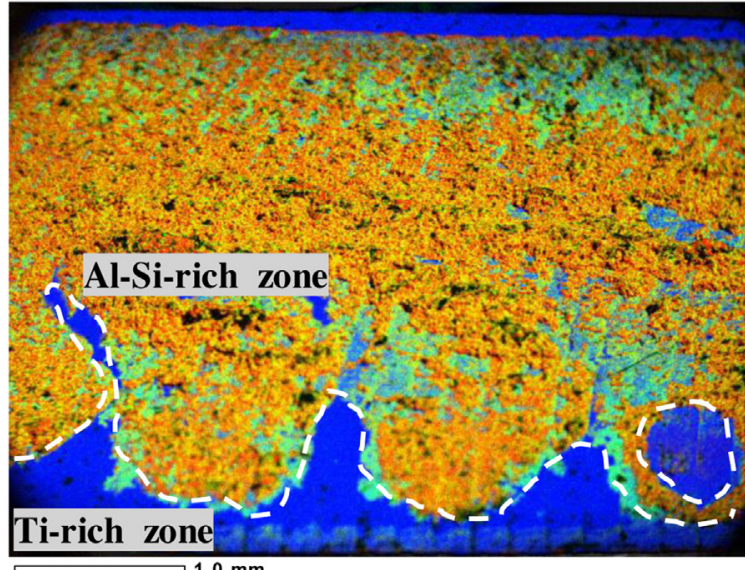

(a)

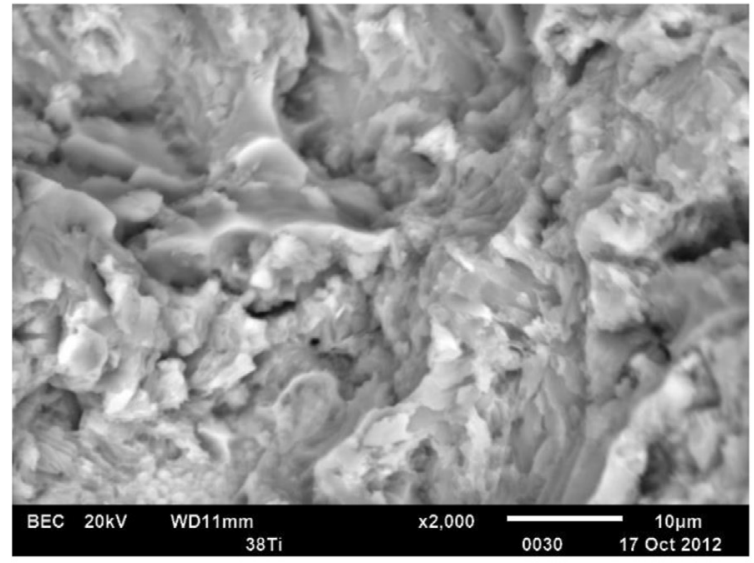

(b)

Fig. 11. Fracture surface in case of crack propagation at T40/MZ interface (sample 3, T40 side): X-map of global view (a); zoom on fracture surface in Al-Si rich zone (b).

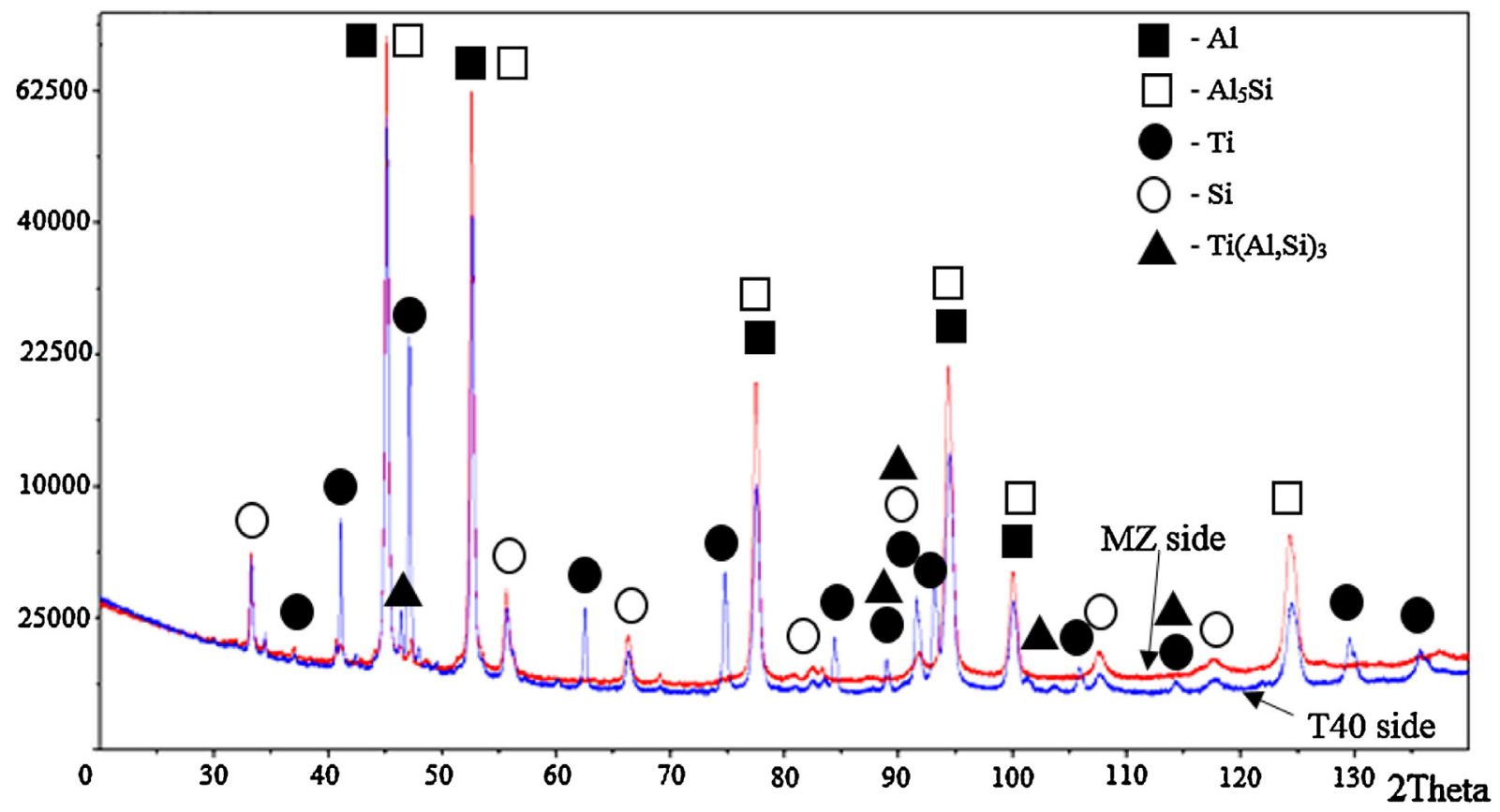

Fig. 12. XRD of fracture surfaces in case of fracture propagation at T40/MZ interface (sample 3).

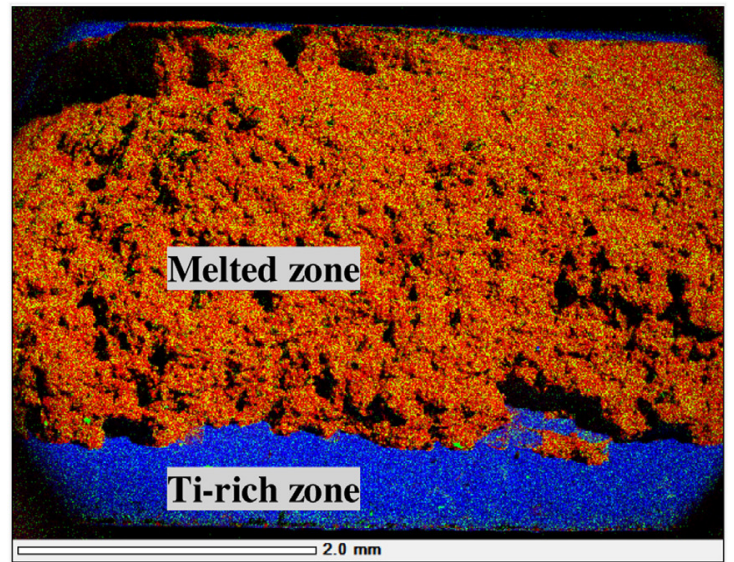

(a)

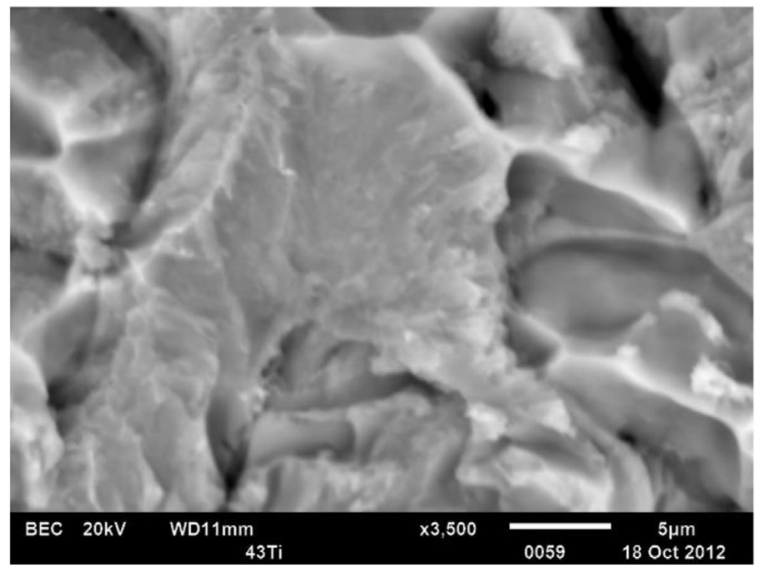

(b)

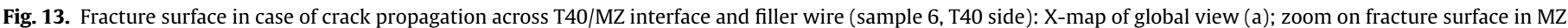
(b). 


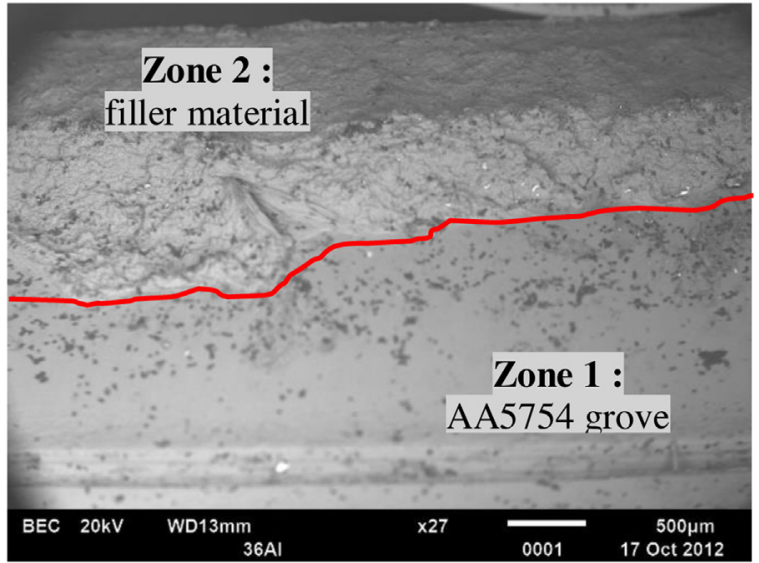

Fig. 14. Fracture surface in case of crack propagation across AA5754/MZ interface (sample 4).

on filler material. According to Raghavan (2005), the solidification on the surface of solid Ti starts with formation of $\mathrm{Ti}_{5} \mathrm{Si}_{3}$ layer by reaction $\mathrm{L} \rightarrow \mathrm{b}-\mathrm{Ti}+\mathrm{Ti}_{5} \mathrm{Si}_{3}$. Earlier Chen et al. (2011b) observed the formation of nanosize granular $\mathrm{Ti}_{7} \mathrm{Al}_{5} \mathrm{Si}_{12}$ phase at solid Ti interface with TEM. However, EDX analysis alone could not confirm or counter the formation of this ternary phase in the present study.

In samples with filler wire 4043 (5\%at Si) (Fig. 7), the interface was uniform and had typical composition of $64 \% \mathrm{at}$. Al, $32 \% \mathrm{at}$. Ti and only $4 \%$ at. Si, which corresponds, according to $\mathrm{Al}-\mathrm{Si}-\mathrm{Ti}$ phase diagram (Liu et al., 2008), to the mixture of $\mathrm{TiAl}_{3}, \mathrm{TiAl}_{2}$ and $\mathrm{Ti}_{5} \mathrm{Si}_{3}$ phases. For the samples with filler wire 4047 (12\%at Si) (Fig. 6), this interlayer was more pronounced and non-uniform. Inner part had a composition of $43 \%$ at. $\mathrm{Al}, 43 \%$ at. Ti and $12 \%$ at. Si, which also corresponds to the mixture of $\mathrm{TiAl}_{3}, \mathrm{TiAl}_{2}$ and $\mathrm{Ti}_{5} \mathrm{Si}_{3}$ phases. In outer part that contains less $\mathrm{Si}$ (67\%at. Al, $22 \%$ at. Ti, 9\%at. Si), the formation of ternary phase $\tau_{2}\left(\mathrm{Al}_{21} \mathrm{Si}_{46} \mathrm{Ti}_{33}-\mathrm{Al}_{8} \mathrm{Si}_{59} \mathrm{Ti}_{33}\right)$ along with $\mathrm{TiAl}_{3}$ was assumed.

Finally, important columnar structures composed of $\mathrm{Ti}(\mathrm{Al}, \mathrm{Si})_{3}$ (78\%at. Al, $19 \%$ at. Ti, $3 \%$ at. $\mathrm{Si}$ ) in case of 4043 wire and of $\mathrm{TiAl}_{3}+\tau_{2}$ (72\%at. Al, 20\%at. Ti, $8 \%$ at. Si) in case of 4047 wire were observed. Si also accumulated in form of a halo around columnar structures. Next followed Al-Si medium composed by eutectic structure in case of 4047 wire and hypotectic structure in case of 4043 wire.

Interface of type 2 (Fig. 8) was usually perceived in the middle of T40/MZ interface. It had morphology similar to type 1 but colum-

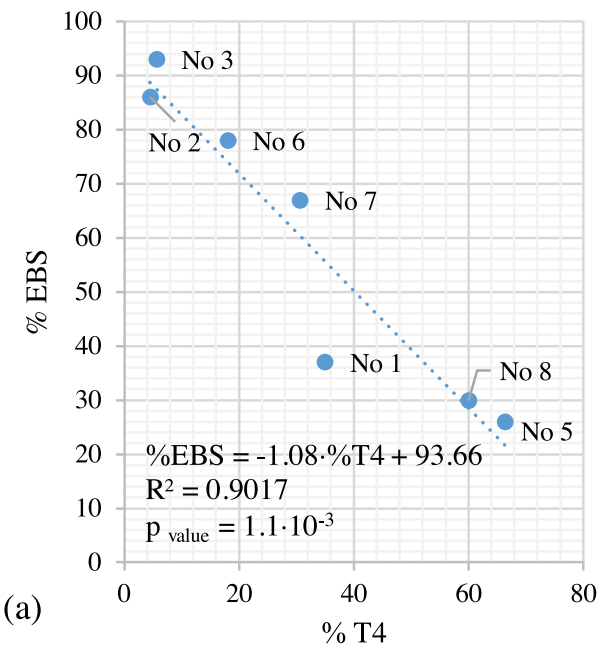

nar structures poor in Si were much less developed. The thickness of the whole interface was comprised within 4-6 $\mu \mathrm{m}$. EDX analysis of the interface allowed supposing the formation of $\mathrm{TiAl}_{3}$ and $\mathrm{Ti}_{5} \mathrm{Si}_{3}$ phases in the inner part of interlayer, when underdeveloped columns were composed by $\mathrm{Ti}(\mathrm{Al}, \mathrm{Si})_{3}$. In case of 4043 filler, the accumulation of $\mathrm{Si}$ at T40/MZ interface was much less pronounced.

Interface of type 3 was observed in the middle and bottom parts of the samples welded with 4047 filler wire (Fig. 9). In this case, eutectic structure of 4047 accumulated at the interface and formed 1.8-2 $\mu \mathrm{m}$ Si-rich layer with petal-like structure. EDX analysis of this interface allowed supposing the formation of $\mathrm{TiAl}_{3}+\mathrm{Ti}_{5} \mathrm{Si}_{3}$ mixture.

Interface of type 4 (Fig. 10) was usually observed in the bottom part of the groove and was associated with use of 4043 filler material. In this case, the only observed structure was a very thin $(<0.5 \mu \mathrm{m})$ Si-rich layer.

For all samples, the expanses of these four types of morphologies at T40/MZ interface were localized with SEM imaging (Fig. A1) and expressed in\% of total interface length (Table A1). The diagram of effects of operational parameters on formation of interface morphologies (Fig. A2) revealed the following tendencies. The morphology of type 1 forms very rarely (only in two samples) and corresponds to the excessive local heating of T40/MZ interface. No statistical conclusion can be made within chosen window of operational parameters. The formation of morphology of type 2 was found to be strongly promoted by use of Si-rich filler wire 4047 (Al12Si), opening angle of $30^{\circ}$ at T40 side of the groove and by laser offset of $0.4 \mathrm{~mm}$ to T40 side. The morphology of type 3 was found in all samples except sample 4 and is strongly promoted by groove opening angle of $45^{\circ}$ at T40 side of the groove and by laser beam offset of $0.9 \mathrm{~mm}$ to T40. The morphology of type 4 was found in all samples except the sample 4 and is strongly promoted by use of filler wire 4043 poor in $\mathrm{Si}\left(\mathrm{Al}_{5} \mathrm{Si}\right)$. p values of influencing factors are provided in Table A2. The disposition of these morphologies along the interface is a complex function of operational parameters and depends on local thermal history of the interface that may be predicted by numerical modeling. In all cases, the morphology of type 4 was situated at the bottom of $\mathrm{T} 40 / \mathrm{MZ}$ interface that remains the coldest part of the melted zone.

\subsection{Fractography}

As shown in Table 4 and on Fig. 4, during the tensile test, fracture occurred in different parts of the joint. In most cases, fracture happened at the interface between T40 and MZ. The global view of

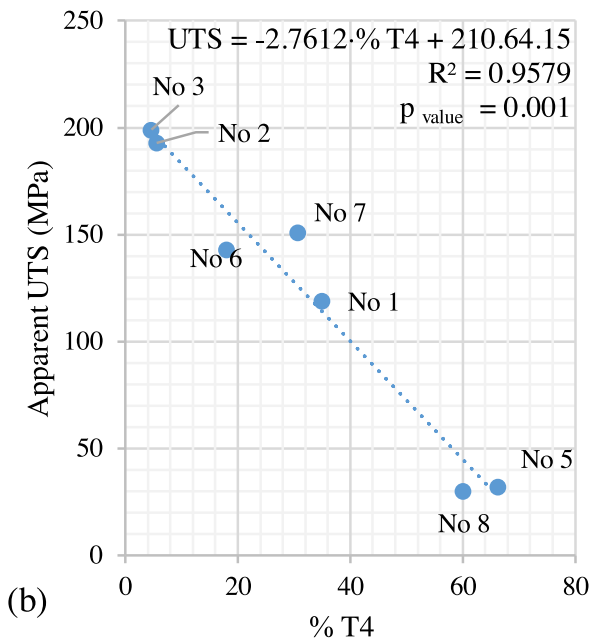

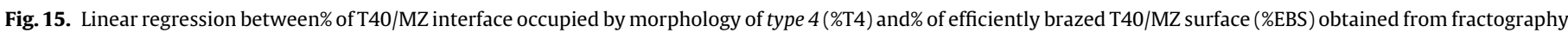
data (a); linear regression between\% of T40/MZ interface occupied by morphology of type 4 (\%T4) and apparent UTS (b). 

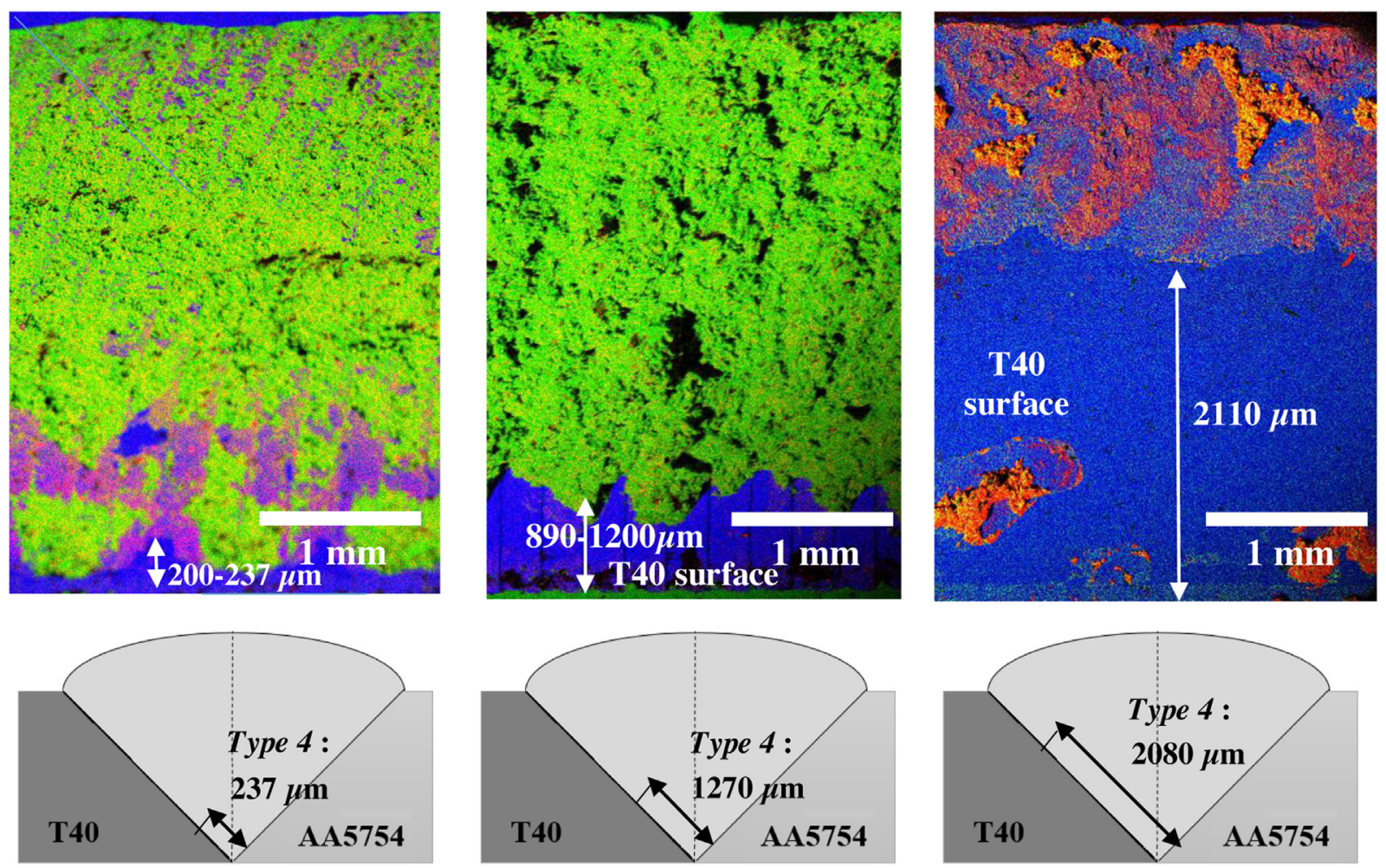

(a)

(b)

(c)

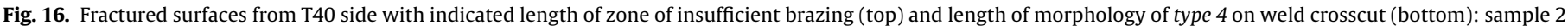
broken at T40/MZ interface (a), sample 7 broken at T40/MZ interface and filler wire (b) and sample 8 broken at T40/MZ interface (c).

fractured surface on T40 side (Fig. 11a) shows two types of zones: rich in $\mathrm{Si}$ and $\mathrm{Al}$, where $\mathrm{Ti}$ is absent (for example, for sample 3: 82 \%at. Al, 0\%at. Ti, $18 \%$ at. Si) and rich in Ti (28\%at. Al, $58 \%$ at. Ti, $13 \%$ at. Si). The tooth-like character of the interface between these two zones corresponds to the periodical arrival of melted filler wire at the bottom of the groove. In Al-Si rich zone, transgranular fracture mode was observed (Fig. 11b). Here, the fracture took place in the proximity of T40 interface, as the concentration of Si was systematically superior to that of filler wire. Visible Ti-rich zone is in fact the surface of T40 groove that suffered from weak adherence of filler material. In this zone, brazing was inefficient due to insufficient energy supply. These zones were generally situated at the middle or bottom of the weld, where T40 obviously did not receive enough heat for starting efficient diffusion process between Ti and filler elements.

XRD analysis showed that all samples broken at T40/MZ interface have fracture surfaces with very close phase content. Two sides of each break also have very close peak intensities (Fig. 12). The dominating phases were $(\mathrm{Al}),(\mathrm{Si}),\left(\mathrm{Al}_{5} \mathrm{Si}\right)$ and $\mathrm{Ti}(\mathrm{Al}, \mathrm{Si})_{3}$, which allowed supposing that the fracture occured in outer layer of T40/MZ interface. Presence of $\alpha$-Ti corresponds to T40 zones with little brazing.

In two samples ( 6 and 7, both with 4043 wire) the fracture was initiated at T40/MZ interface in the zone where lack of brazing is observed (interface of type 4), propagated to the beginning of the zone of effective brazing (interface of type 1,2 or 3) and then continued in the filler metal. This can be seen on fractography of sample 6 , composed by two clearly distinguished zones (Fig. 13a): filler wire with mixed fracture mode (Fig. 13b) and braze free T40 groove. From comparison between fractography and observed structure of T40/MZ interface (Fig. A1), it can be concluded that the interface of type 2 stopped the propagation of the crack along T40/MZ interface. $\mathrm{XRD}$ data for these two samples revealed the presence of $(\mathrm{Al})$ and
( $\mathrm{Si}$ ) solid solutions as well as of $\alpha$-Ti, but no intermetallic phases proper to $\mathrm{T} 40 / \mathrm{MZ}$ interface.

Only in sample 4, a fracture occurred at the interface between AA5754 and MZ, because of the important lack of fusion: it can be seen that zone 1 of unmelted AA5754 dominates over zone 2 corresponding to MZ (Fig. 14). XRD study revealed the presence of $(\mathrm{Al})$ and $(\mathrm{Si})$ solid solutions as well as low quantity of $\mathrm{Mg}_{2} \mathrm{Si}$.

After excluding atypical sample 4, the measurements of fractured surfaces corresponding to the zones of effective brazing at T40 side were made. These results were confronted with normalized expanses of morphology of type 4 at T40/MZ interface, obtained from SEM observation of cross-sections (Fig. A1; Table A1). Strong inverse linear tendency between the expanse of morphologies of type 4 and\% of efficiently brazed T40/MZ surface (\%EBS) was observed (Fig. 15a). The position of zones of inefficient brazing at T40/MZ interface was found in good concordance with location of morphology of type 4 (Fig. 16). In the same time, strong inverse linear tendency between the expanse of morphologies of type 4 and apparent UTS was observed (Fig. 15b). All this allows concluding that morphology of type 4 coincides with the zones of insufficient brazing and thus should be avoided.

Highest tensile strength (sample 3:200 MPa of apparent UTS or $90 \%$ joint coefficient) was obtained when efficiently brazed T40/MZ interface neared $100 \%$. The use of Si-rich filler metal allowed enhancing tensile strength of joints comparing to results of our previous study focused on direct joining between AA5754 and Ti alloy (Tomashchuk et al., 2015), where joint coefficient of only $60 \%$ was reached. Samples 2 and 3, having highest tensile strength and\%EBS, also show quite uniform microstructure of T40/MZ interface (Fig. A1). It means that the shaping of laser beam in double half-spot tandem allowed approaching uniform thickness of brazed $\mathrm{T} 40 / \mathrm{MZ}$ interface for groove opening angle of $45^{\circ}$. 
The combined effect of two statistically significant factors ( $\mathrm{x} 1$ and $\mathrm{x} 6$ ) can also be noticed on Fig. 15b. The group of samples having maximal tensile strength (No 2 and 3 ) corresponds to the combination of favorable values $\left(x 1=4047, x 6=45 / 45^{\circ}\right)$, the weakest samples (No 5 and 8 ) have combination of unfavorable values $\left(x 1=4043, x 6=30 / 45^{\circ}\right)$, when samples with average strength have one of these factors fixed on unfavorable value.

\section{Conclusions}

- Within defined window of operational parameters, statistically important factors that influence the strength of T40 to AA5754 joints in $\mathrm{V}$ groove configuration are: the nature of the filler metal (high Si content should be privileged) and groove opening angle on T40 side (angle of $45^{\circ}$ facilitates the flow of melted wire in the groove).

- The tensile strength of the welds is strongly determined by the proportion between zones of T40/MZ interface having welldeveloped and under-developed structures.

- At top and middle parts of the joints, well developed Si-rich structures with thickness comprised between 25 and $2 \mu \mathrm{m}$ composed by in $\mathrm{Ti}_{5} \mathrm{Si}_{3}, \tau_{2}$ and $\mathrm{Ti}(\mathrm{Al}, \mathrm{Si})_{3}$ were observed.

- The formation of very thin $(<0.5 \mu \mathrm{m}) \mathrm{Si}$-rich interfaces at the bottom of the groove is not sufficient for establishing mechanical continuity of the joint and thus should be avoided.

- Optimal welding condition for joining of $3 \mathrm{~mm}$ thick T40 with AA5754 in butt configuration was identified as: groove opening $45^{\circ} / 45^{\circ}$, filler wire 4047 (Al12Si), laser power of $3.6 \mathrm{~kW}$, filler supply rate of $2.2 \mathrm{~m} / \mathrm{min}$, welding speed $0.45 \mathrm{~m} / \mathrm{min}$, defocusing of $4 \mathrm{~mm}$ and offset of laser from joint line of $0.9 \mathrm{~mm}$ to T40 side. The resulting weld showed joint coefficient of $90 \%$ (or $200 \mathrm{MPa}$ of apparent UTS comparing with AA5754).

- Laser beam configuration in shape of double half-spot tandem was found promising for obtaining uniform microstructure thickness during welding-brazing in V-shaped groove with filler supply.

\section{Acknowledgement}

This work was supported by the French program Institut CARNOT Arts in the frame of the project ATTILA.
Table A1

Normalized expanses ${ }^{\mathrm{a}}$ of different types of T40/MZ interface morphologies, obtained from observation of melted zones crosscuts.

\begin{tabular}{lllll}
\hline \multirow{2}{*}{ No } & \multicolumn{4}{l}{$\%$ microstructure type } \\
\cline { 2 - 5 } & Type 1 & Type $\mathrm{x} 2$ & Type 3 & Type 4 \\
\hline 1 & 0.0 & 62.0 & 3.0 & 35.0 \\
2 & 0.0 & 0.0 & 94.4 & 5.6 \\
3 & 0.0 & 0.0 & 95.5 & 4.5 \\
4 & 4.0 & 96.0 & 0.0 & 0.0 \\
5 & 0.0 & 0.0 & 33.7 & 66.3 \\
6 & 52.0 & 4.7 & 25.3 & 18.0 \\
7 & 0.0 & 16.4 & 53.0 & 30.6 \\
8 & 0.0 & 0.0 & 40.0 & 60.0 \\
\hline
\end{tabular}

a Normalized expanse for every type of interfacial morphology was calculated as $E_{i}(\%)=\frac{\sum l_{i}}{L} \cdot 100$, where $\sum l_{i}-$ total length of morphology of type $i$ and $L$-total
length of T40/MZ interface.

Table A2

$\mathrm{p}$ values of factors influencing formation of different types of microstructure.

\begin{tabular}{lllllll}
\hline & $\mathrm{x} 1$ & $\mathrm{x} 2+\mathrm{x} 3$ & $\mathrm{x} 4$ & $\mathrm{x} 5$ & $\mathrm{x} 6$ & $\mathrm{x} 7$ \\
\hline Type 1 & 0.137 & 0.137 & 0.125 & 0.137 & 0.137 & 0.125 \\
Type 2 & 0.026 & 0.074 & 0.125 & 0.074 & 0.026 & 0.020 \\
Type 3 & 0.110 & 0.132 & 0.152 & 0.179 & 0.028 & 0.030 \\
Type 4 & 0.046 & 0.157 & 0.216 & 0.201 & 0.063 & 0.108 \\
\hline
\end{tabular}

\section{Appendix A.}



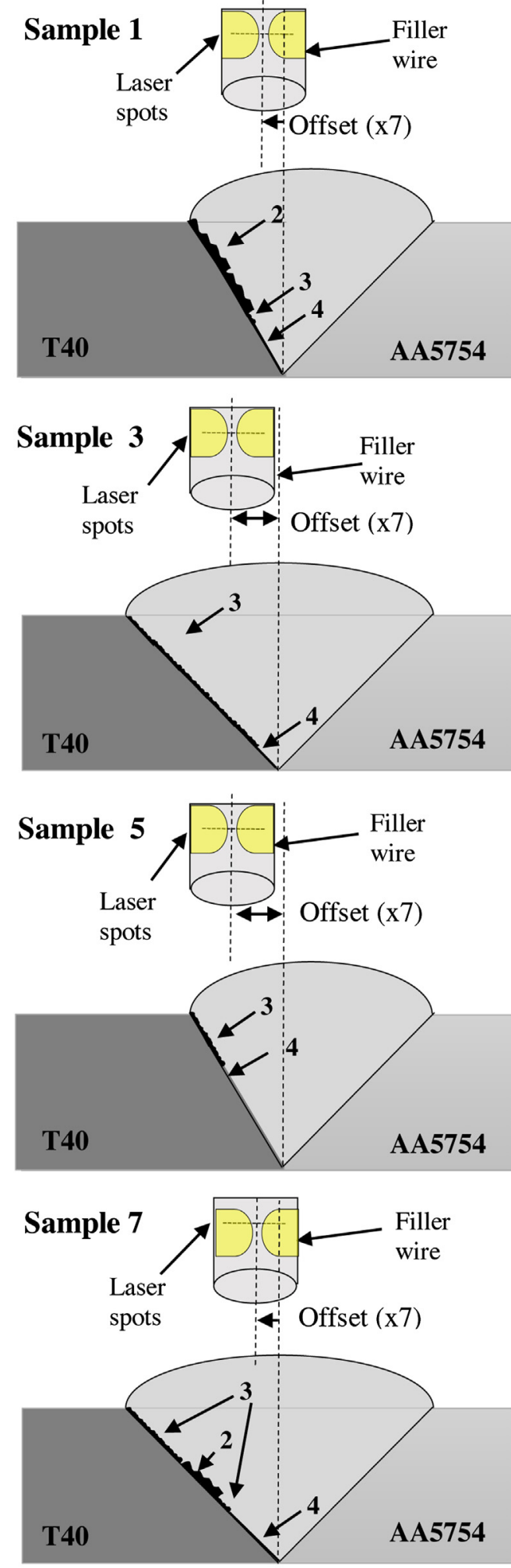

Types of microstructure :

$1-$ up to $13-25 \mu \mathrm{m}$ ind

2-6-5 $\mu \mathrm{m}$
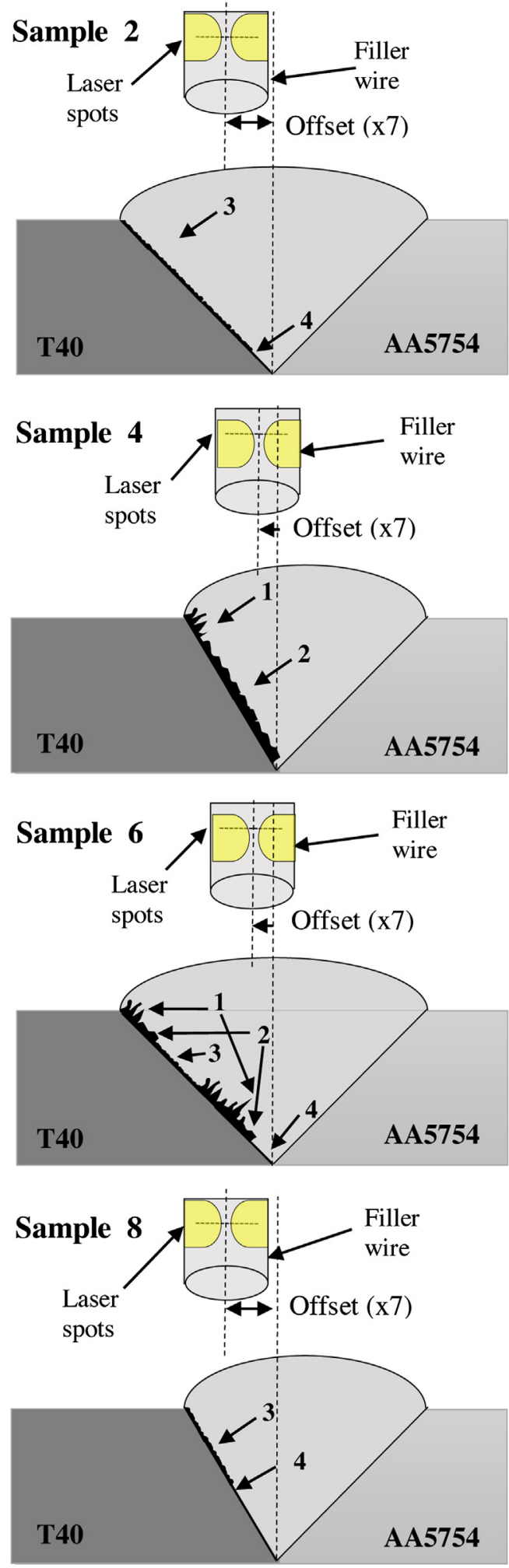

$3-1-2 \mu \mathrm{m}-$
$4-<0.5 \mu \mathrm{m}-$

Fig. A1. Distribution of different types of interface morphologies at T40/MZ interface. 

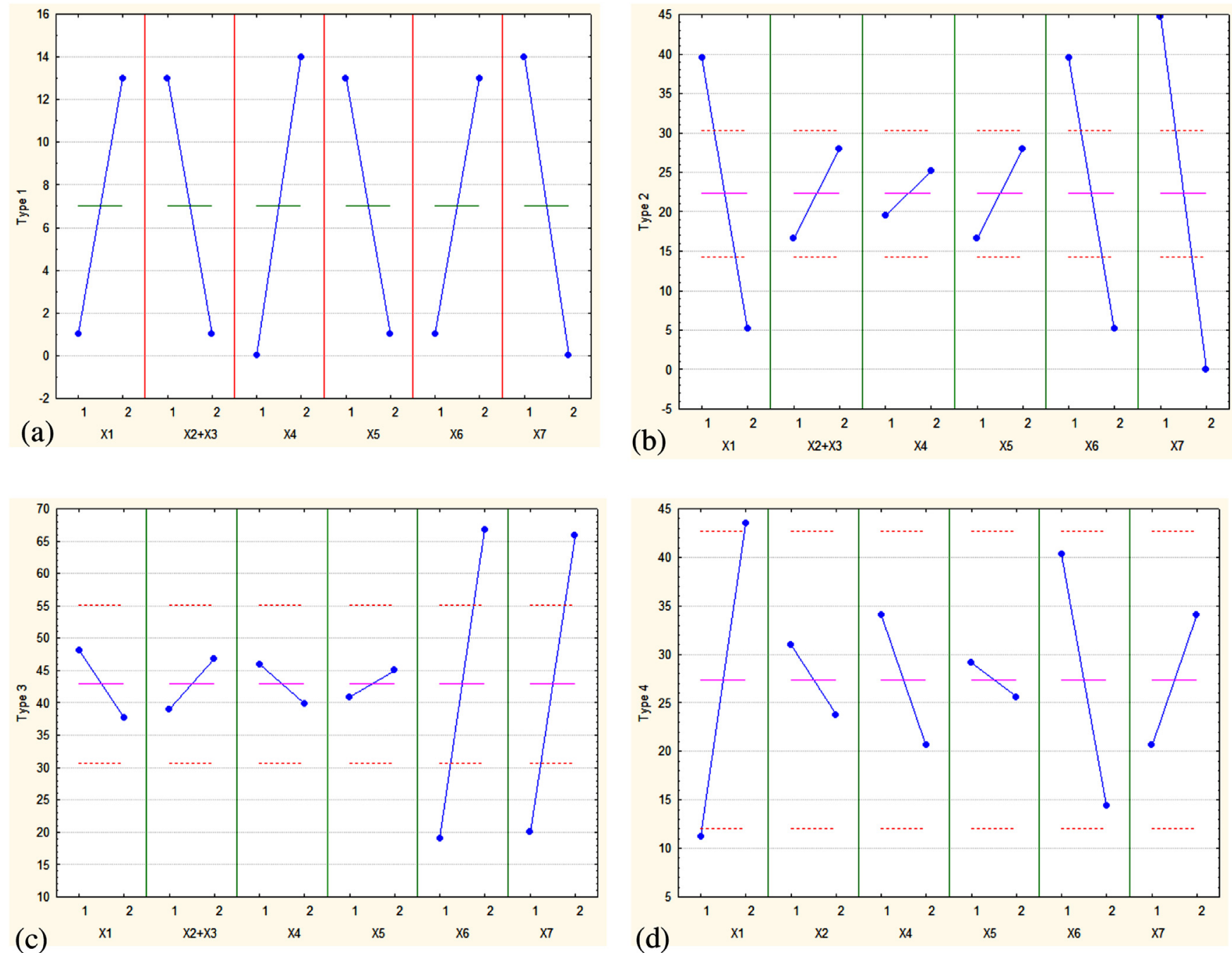

Fig. A2. Diagrams of effects of operational parameters on formation of different types of morphologies at T40/MZ interface: type 1 (a), type 2 (b), type 3 (c), type 4 (d).

\section{References}

Casalino, G., Mortello, M., Peyre, P., 2015. Yb-YAG laser offset welding of AA5754 and T40 butt joint. J. Mater. Process. Technol. 223, 139-149.

Chen, S., Li, L., Chen, Y., Liu, D., 2010a. Si diffusion behavior during laser welding-brazing of $\mathrm{Al}$ alloy and $\mathrm{Ti}$ alloy with $\mathrm{Al}-12 \mathrm{Si}$ filler wire. Nonferrous Met. Soc. China 20, 64-70.

Chen, Y., Chen, S., Li, L., 2010b. Influence of interfacial reaction layer morphologies on crack initiation and propagation in Ti/Al joint by laser welding-brazing. Mat. Design 31, 227-233.

Chen, S., Li, L., Chen, Y., Dai, J., Huang, J., 2011a. Improving interfacial reaction nonhomogeniety during laser welding-brazing aluminum to titanium. Mat. Design 32, 4408-4416.

Chen, S., Li, L., Chen, Y., Liu, D., Huang, J., 2011b. Joining mechanism of Ti/Al dissimilar alloys during laser welding-brazing process. J. All. Comp. 509 891-898.

Gao, M., Chen, C., Gu, Y., Zeng, X., 2013. Microstructure and tensile behavior of laser arc hybrid welded dissimilar Al and Ti alloys. Materials 7, 1590-1602.

Graham, M.P., Weckman, D.C., 1995. A comparison of rotating-wire and rotating-pinhole-type laser beam analysers when used to measure pulsed Nd:YAG laser beams. Meas. Sci. Technol. 6, 1492-1499.

Kreimeyer, M., Wagner, F., Vollertsen, F., 2005. Laser processing of aluminum-titanium-tailored banks. Opt. Lasers Eng. 43, 1021-1035.
Liu, Y., Leong, K.H., 1992. Laser beam diagnostics for kilowatt pulsed Nd:YAG laser. In: Farson, F.D., Steen, W.M., Miyamoto, I. (Eds.), ICALEO'92 Proceedings. Orlando, October, pp. 77-87.

Liu, S., Weitzer, F., Schuster, J.C., Krendelsberger, N., Du, Y., 2008. On the reaction scheme and liquidus surface in ternary system Al-Si-Ti. Int. J. Mater. Res. 99, 705-711.

Majumdar, B., Galun, R., Weisheit, A., Mordike, B.L., 1997. Formation of crack-free joint between Ti alloy and $\mathrm{Al}$ alloy by using a high-power $\mathrm{CO}_{2}$ laser. J. Mater. Sci. 32, 6191-6200.

Peyre, P., Berthe, L., Dal, M., Pouzet, S., Sallamand, P., Tomashchuk, I., 2014. Generation and characterization of T40/A5754 interfaces with lasers. J. Mater. Process. Technol. 214, 1946-1953.

Raghavan, V., 2005. Aluminum-titanium. J. Phase Equilib. Diff. 26, 171-172.

Song, Z., Nakata, K., Wu, A., Liao, J., 2013. Interfacial microstructure and mechanicalproperty of Ti6Al4 V/A6061 dissimilar joint by direct laser brazing without fillermetal and groove. Mater. Sci. Eng. A 560, 111-120.

Tomashchuk, I., Sallamand, P., Cicala, E., Peyre, P., Grevey, D., 2015. Direct keyhole laser welding of aluminum alloy AA5754 to titanium alloy Ti6Al4V. J. Mater. Process. Technol. 217, 96-104.

Vaidya, W.V., Horstmann, M., Ventzke, V., Pertovski, B., Koçak, M., Kocik, R., Tempus, G., 2010. Improving interfacial properties of a laser beam welded dissimilar joint of aluminum AA6056 and titanium Ti6Al4V for aeronautical applications. J.Mater. Sci. 45, 6242-6254. 